\title{
CONHECIMENTO DA ATENDENTE DE ENFERMEGEM SOBRE ALGUNS CUIDADOS PRESTADOS AO RECÉM-NASCIDO PREMATURO
}

\author{
Miriam Aparecida Barbosa Merighi*
}

MERIGHI, M.A.B. Conhecimento da atendente de enfermagem sobre alguns cuidados prestados ao recém-nascido prematuro. Rev. Esc. Enf. USP, São Paulo, 23(3): $\longrightarrow$, ago. 1989.

Este estudo teve como objetivo verificar o conhecimento da atendente de enfermagem que trabalha em berçário de prematuro no pertodo noturno sobre as caracteristicas físicas destes recém-nascidos e sobre alguns cuidados de enfermagem que devem ser dispensados aos mesmos, estando ou nâo com complicaçöes. A população do estudo foi constitutda de 33 atendentes de enfermagem de 12 hospitais da Grande São Paulo. Os dados foram colhidos por meio de entrevistas, utilizando-se um formulário estruturado. Adotou-se um critério eclético para a avaliação do-conhecimento das atendentes, o qual foi classificado nas categorias: "Muito Bom", "Bom", "Regular" e "Insuficiente". De acordo com os dados obtidos, verificou-se que as atendentes de enfermagem tem conhecimento classificado, segundo os critérios estabelecidos, como: "Bom', com relação às caracterlsticas flsicas do prematuro e alguns cuidados de enfermagem dados ao mesmo estando ou não com complicaçōes.

UNITERMOS: Atendente de enfermagem. Prematuro. Enfermagem neonatal.

\section{INTRODUÇÃO}

A prematuridade constitui, atualmente um dos maiores problemas da pediatria e tem sido estudada por vários autores.

Considerando que o critério peso do recém-nascido pode caracterizar a prematuridade, a ACADEMIA AMERICANA DE PEDIATRIA (1957) adotou a seguinte detinição de prematuro e de recém-nascido de baixo peso para a idade gestacional: "prematuro é toda a criança nascida viva com período de gestação de menos de 37 semanas completas e recém-nascidos de baixo peso é a criança nascida viva com peso de $2500 \mathrm{~g}$ ou menos".

O CENTRO DE ESTUDOS PERINATAIS DE SĀO PAULO (1972) adota a mesma classificação de prematuro recomendada, em 1964, pela "Standards and Recomendations for hospital care of newborn infants, A.A.P.", que é a seguinte: "Prematuro é toda criança nascida viva com período de gestaçảo de menos de 37

* Enfermeira. Professor Assistente do Departamento de Enfermagem Matemo-Infantil e Psiquiátrica da Escola de Enfermagem da USP. 
semanas completas, ou seja, até 36 semanas e 6 dias". Portanto, prematuridade é a qualidade ou condição do prematuro. Quanto à conceituaçāo de recém-nascido de baixo peso, o CENTRO DE ESTUDOS PERINATAIS DE SĀO PAULO (1972) considera, para fins estatísticos todos aqueles que pesam, ao nascer, $2.500 \mathrm{~g}$ ou menos. CORRIDINI et alii (1978) consideram recém-nascido de baixo peso ao nascimento "todo aqule que nasce com $2.500 \mathrm{~g}$ ou menos, independente do tempo de gestação".

Segundo ORLANDI (1954), nenhum outro serviço médico exige tanto da enfermagem como uma unidade de prematuros. $O$ autor destaca que a base principal para se conseguir bons resultados em um berçário está na escolha de uma equipe de enfermagem quantitativamente e qualitativamente bem preparada. De nada adiantam modernos equipamentos, como por exemplo, incubadoras, monitores, material em quantidade suficiente, se não houver enfermeiras especializadas, atentas, vigilantes e capazes, prontas para atender o prematuro a qualquer momento e em qualquer emergência. É importante que se mantenha um padrão elevado de assistência de enfermagem ao prematuro durante as 24 horas do dia, sem interrupção.

CROSSE (1957) considera a prematuridade como uma causa importante e crescente no coeficiente de mortalidade infantil. $O$ autor destaca que uma das prevençōes da diminuição da morbidade e da mortalidade neonatal é a assistência ao recém-nascido, durante e após um parto prematuro inaceitável.

A ACADEMIA AMERICANA DE PEDIATRIA (1957) recomenda que para se proporcionar uma atenção eficaz ao prematuro deve-se levar em consideração o peso, o seu estado físico, a política médica relacionada com a prematuridade, o programa de educação aos pais, o programa de educação dos estudantes de medicina e de enfermagem e a educação em serviço realizado no berçário. São de especial importância: a supervisão do pessoal que compōe a equipe de enfermagem que assiste ao recém-nascido prematuro; a proporção entre o número de pessoal de enfermagem e o número de prematuros; o preparo do pessoal auxiliar que compõe a equipe e dos estudantes de enfermagem e de medicina que usam o berçário como campo de estágio.

Os cuidados de enfermagem ao prematuro devem estar sob a direção de uma enfermeira diplomada, com estudos especializados e experiência em cuidados com prematuros.

$\mathrm{O}$ yeso e o estado físico dos prematuros são fatores que devem ser levados em considieração para se estabelecer a proporção entre o número de prematuros e enfermeiras necessárias para seu cuidado. Segundo a publicação da ACADEMIA AMERICANA DE PEDIATRIA (1957) uma enfermeira para cada 5 prematuros é uma proporção razoável. Isto resultaria em 5 horas de cuidados de cada enfermeira para cada prematuro. Os cuidados de enfermagem de todos os prematuros devem ser realizados segundo uma distribuição de tarefas diárias pela supervisora de en- 
fermegem, de acordo com o estado do prematuro e com a capacidade dos membros dessa equipe. $O$ pessoal de enfermagem destinado aos cuidados de prematuros não deve trabalhar em outras unidades do hospital.

LLORENS et alii (1972) afirmam que o papel do pessoal auxiliar é de grande importância, dele dependendo quase sempre os êxitos e os fracassos na evolução do prematuro. O esforço requerido pela equipe médica e pelo pessoal auxiliar para salvar a vida de um prematuro junto com os recursos físicos, clínicos, laboratoriais e outros, na assistência a mesmo, são demais custosos para que se percam tantos esforços por um simples descuido de um profissional. Por isso toda medida de disciplina e controle exigida ao pessoal auxiliar deve ser levada a êxito. Os componentes da equipe que trabalham num berçário de prematuros devem gozar de perfeita saúde. Toda enfermeira com piodermite, gastroenteriterocolite, ou mesmo com um simples resfriado, tem de ser afastada momentaneamente.

ROSSIER (1974 b) descrevendo sobre a organização prática de um centro de prematuros, considera que está em primeiro plano a funçāo do pessoal, que deve ser qualificado, com especialização para dar assistência ao prematuro. Este autor, como ORLANDI (1954), destaca que os locais e os equipamentos mais perfeitos, de nada servem se näo houver pessoal qualificado para utilizá-lo. ROSSIER (1974 a) considera importante que o pessoal auxiliar, em número suficiente, trabalhe sob o controle de enfermeiras especializadas em puericultura. Para ele uma unidade de 15 prematuros deverá contar com 13 ou 15 funcionárias adestradas para esta assistência, nas 24 horas.

Para LANCASTER \& ROBERTS (1972) nenhum problema $e$ mais difícil do que prover pessoal, em número e qualidade adequados, para atender eficientemente o recém-nascido prematuro. Estes autores aconselham que, nos berçários de prematuros, haja uma equipe de enfermagem, devidamente treinada e com experiência, da qual devem constar: enfermeiras especializadas em neonatologia, técnicos de enfermagem, auxiliares de enfermagem e demais funcionários; para cada turno deve haver uma enfermeira para 2 recém-nascidos que exigem o máximo de cuidado e uma enfermeira para 3 ou 6 recém-nascidos que necessitem de menos cuidados. LANCASTER \& ROBERTS (1972) comentam, também, que ao se calcular o número necessário de pessoal para as 24 horas, deve-se considerar 4,2 horas de cuidado direto para cada recém-nascido prematuro, em cada turno.

MONETTI \& CARVALHO (1976), como outros autores anteriormente citados, destacam a importância dos serviços de assistência ao recém-nascido estarem a cargo de uma enfermeira diplomada; também fazem as mesmas recomendaçōes quantó ao preparo, ao número e ao tempo de serviço dos membros da equipe do berçário.

Como podemos constatar, diversos autores dāo ênfase na importância dos cuidados físicos ao prematuro. Para eles a equipe de enfermagem com experiência e conhecimentos quanto aos cuidados com os prematuros é essencial; da dedicação 
e eficiência de cada um dos seus membros depende grande parte do sucesso obtido em um berçário.

Parece-nos que nos berçários de prematuros existe muita dificuldade com relaçäo ao pessoal, tanto em número como em qualidade; sabe-se que o ideal seria manter no berçário, para o cuidado direto do prematuro, apenas enfermeiras e auxiliares de enfermagem. Contudo isso é difícil no nosso meio, provavelmente, pela escassez desses profissionais e por ser mais oneroso para o estabelecimento hospitalar. Esta dificuldade obriga, muitas vezes, o emprego de atendentes para o cuidado de prematuros que, na maioria das vezes, são pessoas dedicadas, com a máxima boa vontade, mas que não possuem conhecimentos científicos básicos para esta assitência e para compreender determinadas situações, afim de agir com presteza, de maneira racional e objetiva, nas mesmas.

Estudamos anteriormente o conhecimento das atendentes de enfermagem que trabalham no período diurno em relação ao recém-nascido prematuro e os cuidados de enfermagem dados a estes recém-nascidos, e verificamos que as atendentes da amostra, de modo geral, tiveram conhecimento sobre características físicas do prematuro e alguns cuidados de enfermagem aplicados ao mesmo estando ou não com complicaçōes.

$O$ índice de respostas classificadas segundo o critério estabelecido como "Muito bom" e "Bom" foi bem maior em relaçāo ao índice de respostas classificadas como "Regular" e "Insuficiente".

Como o serviço do berçário de prematuro é contínuo durante as $24 \mathrm{~h}$ procuramos rever bibliografias sobre os problemas do horário noturno no pessoal de enfermagem.

Segundo MAURO et alii (1976) dentre os problemas que mais afetam o trabalhador, ressalta-se em especial a fadiga, que nāo sendo uma enfermidade, causa no indivíduo mal estar com alteraçōes em seu estado psicossomático, conseqüentemente ocasionando-lhe insegurança, irritabilidade, agressividade, intolerância a ruídos, dificuldades de concentração, propensão a enfermidades e com maior freqüência as doenças infecciosas e maior propensão à riscos de acidentes.

A fadiga traduz-se sobretudo por uma baixa na perícia com que o indivíduo axecuta seu trabalho, diminuição da coordenação dos movimentos e falta de pecisão na sua execuçāo.

Segundo MILLER-BURT (1973) até o presente momento, não são conhecidas todas as causas de fadiga; todavia qualquer que seja sua origem, a evidência da mesma já é um alerta para a necessidade do repouso e do laser, intercalados nos períodos normais de trabalho.

TURNER (1964) afirma que o sono é considerado uma das necessidades básicas do organismo. É o momento em que os tecidos do corpo aproveitam para reparar suas perdas. $O$ homem não consegue permanecer mais que 10 dias sem dor- 
mir, portanto é uma necessidade que deve ser atendida em intervalos periódicos. $\mathrm{O}$ sono como uma necessidade básica do organismo é tão importante que serve para determinar o poder de produção do indivíduo.

MOURA et alii (1980) afirmam que para os funcionários de maneira geral há vantagens financeiras em se fazer o plantão noturno. Porém, apesar de um repouso de aproximadamente oito horas após o trabalho o pessoal não se sente bem fisicamente.

Poderíamos observar que a preocupaçāo dos autores que descrevem as implicaçōes do serviço noturno é o decréscimo do rendimento deste pessoal. Sabemos também que a noite o número de pessoal é bem menor e que há necessidade da atendente ter maior conhecimento para identificar os sinais e sintomas apresentados pelo recém-nascido prematuro. Devido a estes fatores parece-nos imprescindível que saibamos quais são os conhecimentos das atendentes que cuidam do prematuro em berçários, no período noturno, referentes tanto às características físicas do prematuro como aos cuidados do prematuro sem e com complicaçōes.

Portanto nosso objetivo foi:

- verificar o conhecimento que as atendentes têm sobre as características físicas do prematuro e de alguns cuidados de enfermagem que devem ser dispensados ao mesmo, estando ou não com complicações.

\section{METODOLOGLA}

A população deste estudo foi contituída de atendentes que trabalham durante a noite em berçários de prematuro, em 12 hospitais da cidade de São Paulo.

Os dados foram obtidos por meio de entrevista individual e anotados em formulário estruturado (anexo) pela própria pesquisadora. Este formulário compöe-se de duas partes, como segue: a) dados gerais da atendente; b) dados sobre o seu conhecimento a respeito do prematuro e dos cuidados de enfermagem que ele deve receber.

Os dados foram coletados no período de agosto a outubro de 1983.

\section{RESULTADOS E COMENTÁRIOS}

Fizeram parte deste estudo 33 atendentes de enfermagem. Destas, 11 $(33,34 \%)$ encontravam-se na faixa etária de 25 a 35 anos, seguidas de $8(24,24 \%)$ que estão na faixa etária de 15 a 25 anos.

Quanto ao tempo de trabalho em berçário de recém-nascido prematuro, verificamos que $15(45,46 \%)$ das atendentes do estudo trabalhavam de 1 a 3 anos em berçário de prematuro, e somente 4,6 anos ou mais.

Sabemos que o tempo de trabalho da atendente no berçário é importante, pois o convívio da mesma com as dificuldades encontradas ao assistir o recém- 
nascido prematuro, assim como a orientação de outros membros da equipe de enfermagem ou de médicos da unidade, poderá determinar mudança nos seus conhecimentos em relação à assistência ao recém-nascido prematuro.

Quanto à escolaridade, constatou-se que agrupando-se os dados referentes à escolaridade até o $2^{\circ}$ ano do $1^{\circ}$ ciclo ao $6^{\circ}$ ano do $1^{\circ}$ ciclo houve $30(90,90 \%)$ atendentes representando a maioria da amostra deste estudo.

Para evitar viciar a amostra procurou-se fazer a entrevista nos horários de troca de turno, em lugar fora do berçário, entrevistando-se antes a atendente que irá deixar o mesmo e depois a que irá iniciar o turno de trabalho. Evitou-se assim, que uma transmitisse à outra informaçōes sobre formulário.

Os conhecimentos foram avaliados segundo os critérios assim estabelecidos: "Muito Bom" serão incluídas as atendentes que tiveram até $100 \%$ de acerto nas questōes formuladas.

"Bom", até 70\% de acerto; "Regular", até $40 \%$ de acerto e "Insuficiente", nenhumas resposta certa.

Em relação a orientação destas atendentes, constatamos que a grande maioria, era da responsabilidade da enfermeira - $23(69,69)$. Outros profissionais foram responsáveis pela orientação no serviço de $10(30,31)$ atendentes; destes, 7 $(21,21)$ eram auxiliares de enfermagem e $3(9,10)$ médicos pediatras.

É importante destacar que nos hospitais onde se realizou esta pesquisa, a orientação das atendentes era feita apenas no período em que elas estavam de plantão.

Sabe-se que uma das funções da enfermeira é treinamento, educação e orientaçāo do pessoal que trabalha com prematuro, já que no nosso meio o pessoal de enfermagem qualificado é insuficiente. Em berçário de recém-nascido prematuro, a supervisão e a orientação proporcionadas pela enfermeira às atendentes de enfermagem contribui para o aprimoramento dos conhecimentos destas atendentes sobre cuidados a recém-nascido prematuro. Contudo um fato que constatamos foi que em apenas 3 (25\%) hospitais amostra, os profissionais ministraram aulas relacionadas com os cuidados diários do recém-nascido prematuro, para as atendentes que cuidam dos mesmos.

Quanto ao conhecimento sobre características físicas do prematuro notamos que $24(72,72 \%)$ das atendentes da amostra classificaram-se com conhecimento "Bom" e $9(27,28 \%)$ com conhecimento "Regular". Chamou a atenção o fato de nenhuma atendente do noturno ter conhecimento "Muito Bom" sobre "características físicas do prematuro", dados visíveis e imprescindíveis para a assistência a este recém-nascido, como foi mencionado anteriormente, por vários autores, a assistência de enfermagem ideal está relacionada com as deficiências apresentadas pelo prematuro. 
Em relação à questão observação do prematuro nas 1 as $24 \mathrm{~h}$ de vida nenhuma atendente classificou-se na categoria "Muito Bom"; $23(69,69 \%)$ incluem-se no conhecimento "Bom" e $10(30,31 \%)$ no conhecimento "Regular".

É interessante observar que nenhuma das 33 atendentes da amostra demonstraram ter conhecimento correto da observação do prematuro nas primeiras 24 horas de vida. Isto porque, principalmente neste período o recém-nascido prematuro exige cuidados especializados e intensivos, pois apresenta imaturidade de todos os sistemas (pulmonar, cardiovscular, gastrointestinal, renal e nervoso), podendo-se prever que terá problemas, além de outros, com a manutenção de temperatura e da respiração. A enfermeira deve estar atenta às várias carências simultâneas, imediatas e a longo prazo, desses sistemas. Além disso é necessário observar e anotar as eliminaçooes de fezes, urina, vômitos e possíveis hemorragias (principalmente do coto umbilical) que são sinais precoces de complicaçōes que exigem assistência imediata.

ZIEGEL \& CRANLEY (1980) ressaltam que a enfermeira precisa estar alerta na observação dos recém-nascidos que necessitam de um período de transição mais longo que o habitual, como é o caso do prematuro.

Portanto, cada criança a despeito da normalidade da sua história pregressa, deve ser atentamente observada para receber cuidados de enfermagem adequados.

Constatou-se ainda, que $25(75,75 \%)$ das atendentes emitiram respostas classificadas com conhecimento "Muito Bom" e $8(24,25 \%)$ com conhecimento "Bom" em relaçāo a questão "hidratação do prematuro".

Esta assistência é muito importante pois segundo KLAUS \& FANAROFF (1982), os prematuros são particularmente vulneráveis à excessiva perda de líquidos no princípio neonatal, porque sua pele contém mais água, a epiderme é mais fina e a permeabilidade cutânea é maior. Por esse motivo o recém-nascido prematuro necessita receber grande quantidade de água, pois esta é facilmente eliminada por via gastrintestinal, por evaporação pela pele e pelos pulmōes. Esta situação é agravada pela imaturidade dos rins, que neste período da vida funciona limitadamente quanto à retenção de água no organismo.

ZIEGEL \& CRANLEY (1980), aconselham oferecer água com freqüência quando a ingestão de leite é inadequada devido à sucção ineficiente. Mesmo quando a ingestão de leite é inadequada é necessário oferecer água em todos os intervalos entre as mamadas devido à necessidade hídrica.

Geralmente inicia-se a hidratação de prematuro após as primeiras $6 \mathrm{~h}$ de vida, isto satisfará tanto suas necessidades calóricas como de glicose.

Quanto à alimentação do prematuro com mamadeira notou-se que 8 atendentes $(24,25 \%)$ deram respostas classificadas como "Muito Bom" em relaçāo a este cuidado. Contudo é interessante notar que $24(72,72 \%)$ tem conhecimento "Bom" e 1 atendente $(3,03 \%)$ "Regular". 
Sabe-se que a observação da alimentaçāo do prematuro é de importância fundamental, nos seguintes aspectos: estar atenta à aceitação ou não da alimentação; verificar quando o recém-nascido regurgita para prevenir a aspiração de alimento ou mucosidade; estar alerta em relação ao bico da mamadeira que, deve ser macio, com o orifício não muito pequeno, e cuidar para que o mesmo esteja sobre a língua; elevar a cabeça e o ombro do recém-nascido prematuro para alimentá-lo; interromper a alimentaçāo quando o recém-nascido apresentar dificuldade respiratória; diminuir a quantidade de alimento ou suspender a alimentação toda vez que o recém-nascido regurgitar.

Como pode-se constatar o recém-nascido prematuro exige da enfermeira muita habilidade e paciência na administração de alimento. A não observação dos cuidados durante a alimentação do prematuro pode levar a conseqüências sérias e, muitas vezes, à morte.

É importante verificar que a minoria das atendentes não estão aptas a administrar adequadamente a alimentação com mamadeira ao prematuro.

Em relação à "alimentação do prematuro com sonda naso-gástrica", das 33 atendentes da amostra, 11 atendentes $(33,33 \%)$ incluem-se no conhecimento "Muito Bom", seguidas de 22 atendentes $(66,67 \%)$ no conhecimento "Bom".

As complicaçōes da administração de alimentos ao prematuro pela sonda comum quando não é feita com precisão, são graves e muitas vezes fatais, portanto, neste cuidado não se pode admitir um conhecimento parcialmente correto. Como o número de atendentes que se classificaram com conhecimento "Bom"corresponde a $22(66,67 \%)$, a enfermeira deve estar atenta para uma maior orientação quanto a esta técnica tão importante ou rever se esta atividade pode continuar como uma atribuição deste ocupacional.

A questão como deve ser passada a sonda naso-gástrica foi respondida apenas pela atendente que referiu exercer essa atividade no berçário onde trabalha. Assm obtivemos respostas de 29 atendentes $(55,76 \%)$ da amostra que afirmaram saber passar a sonda naso-gástrica em recém-nascido prematuro; $12(11,37 \%)$ incluem-se no conhecimento "Muito Bom" e $17(58,13 \%)$ no conhecimento "Bom".

A sonda naso-gástrica deve ser introduzida pelo médico ou pela enfermeira, pela importância e responsabilidade desta técnica, já que a nāo observação correta da mesma pode trazer problemas sérios ao recém-nascido, como por exemplo a aspiração do alimento. Entretanto, em muitos berçários esta funçāo é delegada às atendentes, por insuficiência no número daqueles profissionais.

Analisando os dados apresentados acima, podemos verificar que a maioria das atendentes da amostra não estāo preparadas para executar esta técnica.

Portanto, as atendentes devem ser treinadas adequadamente para que executem a técnica da sondagem naso-gástrica corretamente, quando for estritamente necessário, isto é, quando a enfermeira ou o médico não estiverem presentes. 
Quanto ao cuidado com o prematuro após a alimentação apenas $5(15,15 \%)$ das atendentes classificaram-se dentro do conhecimento "Muito Bom", sendo que $28(84,85 \%)$ inluem-se na categoria "Bom".

$O$ cuidado de enfermagem prestado ao recém-nascido prematuro após a alimentação é tão importante quanto o método de adminstrá-la; qualquer displicência profissional nestes cuidados pode levar a conseqüências drásticas; como por exemplo, a aspiração do alimento regurgitado ou vomitado.

Do total das atendentes da amostra, somente $3(9,09 \%)$ incluem-se no conhecimento "Muito Bom" quanto à questão sobre "técnica do banho na incubadora". A maior parte das atendentes, $23(69,69 \%)$ estão agrupadas no conhecimento "Bom". Destaca-se que $7(21,21 \%)$ se incluem no conhecimento "Regular".

O conhecimento sobre "cuidado com a pele do prematuro para evitar infecção", é complemento sobre "Técnica do banho do prematuro na incubadora".

Embora estes conhecimentos sejam imprescindíveis na assistência de enfermagem, nota-se que os conhecimentos classificados como "Bom" compreendem a maior parte desta população, $(69,69 \%$ e $60,60 \%)$ respectivamente.

BETHEA (1977), CORRADINI et alii (1978), comentam que o pessoal que proporciona cuidados ao prematuro deve conhecer sua grande susceptibilidade à infecção e fazer todo o possível para protegê-lo contra ela. Algumas das medidas de enfermagem que podem ajudar a prevenir infecção no prematuro são a prática rigorosa de assepsia e evitar lesōes da pele, além de outras. Consideram que a pele do prematuro é extremamente delicada a menor erosāo, sendo porta de entrada de germes.

Quanto ao conhecimento sobre "cuidado com o coto umbilical", observamos pelo exposto que a maioria das atendentes classificaram-se no conhecimento "Muito Bom", $20(60,60 \%)$ e o restante $13(39,40 \%)$ no conhecimento "Bom".

O cuidado com o coto umbilical é muito importante na profilaxia de infecções graves, destacando-se entre elas o tétano neonatal, considerado por ARAÚJO (1978) e por SCHAFFER \& AVERY (1979) como a mais séria das infecçōes umbilicais. VERONESI et alii (1978) afirmam que o coto umbilical é o principal foco infeccioso do tétano no recém-nascido, Portanto, o cuidado com o coto umbilical merece especial atenção da equipe de enfermagem que assiste ao recém-nascido.

Na questão sobre, cuidado com o prematuro que está apresentando monilíase, a maioria das atendentes classificou-se na categoria de conhecimento "Muito Bom" $16(48,49 \%)$ seguidas de $15(45,45 \%)$ no conhecimento "Bom" e 2 $(6,06 \%)$ no conhecimento "Insuficiente".

ZIEGEL \& CRANLEY (1980) comentam a importância da assistência de enfermagem na próilaxia e no tratamento da monilíase. Segundo os autores a enfer- 
meira deve inspecionar diariamente a boca do RN; placas brancas, ásperas, lembrando coágulos de leite sāo observados na língua, nas gengivas, no palato e na face interna das bochechas. Essas placas não se desprendem com facilidade. A infecção pode disseminar aos outros recém-nascidos pelo manuseio descuidado dos suprimentos alimentares. A Candida albicans (Monilia) está presente nas fezes das crianças infectadas, portanto é indispensável a manipulação cuidadosa das fraldas e a lavagem das mãos com técnica asseptica após o cuidado do recém-nascido para controlar esta infeç̧āo.

Em relação aos cuidados prestados ao prematuro que está com problemas respiratórios observamos que a maioria das atendentes classificaram-se na categoria de conhecimento "Bom", $23(69,69 \%)$, as restantes $9(27,28 \%)$ no conhecimento "Muito Bom" e 3,03\%, "Insuficiente".

Verifica-se que 27 atendentes $(81,82 \%)$ classificaram-se na categoria "Bom" na questão no 23 sobre "controle da umidade da incubadora" e 33 atendentes (100\%) incluem-se na categoria "Bom", na questão sobre cuidado com o prematuro que está recebendo oxigênio. Estes conhecimentos relacinam-se entre si e sāo de suma importância para facilitar a respiração do prematuro. Entretanto nenhuma atendente classificou-se no conhecimento "Muito Bom" quanto a estas questōes.

Autores como LLORENS et alii (1972), CORRADINI et alii (1978), ARAUJO (1978), ZIEGEL \& CRANLEY (1980), KLAUSS \& FANAROFF (1982) são unânimes em afirmar que é imprescindível a regulação de oxigênio, ar fresco e umidade da incubadora para facilitar a respiração. Se o prematuro respira e não está cianótico pode prescindir de oxigênio. Se precisar de oxigênio a concentração do mesmo deve ser de 30 a 40\%; concentraçōes elevadas e excessivas de oxigênio pode provocar complicaçōes irreparáveis, como a fibroplastia retrolental.

Parece de máxima importância que a atendente que cuida destes recém-nascidos tenha conhecimento correto sobre como fazê-lo. Contudo, apenas 9 $(27,28 \%)$ atendentes deste estudo estāo incluídas no conhecimento "Muito Bom" sobre cuidados do prematuro com problemas respiratórios.

Quanto ao conhecimento sobre o cuidado do recém-nascido prematuro com diarréia, nota-se que 13 atendentes $(39,40 \%)$ classificaram-se com conhecimento "Muito Bom", seguidas de 19 (57,57\%) com conhecimento "Bom" e $1(3,03 \%)$ com conhecimento "Regular".

Sabe-se que a diarréia, no período neonatal, é temível pela alta mortalidade jue determina, especialmente em prematuros. MORLEY (1980) comenta que as epidemias de diarreia aguda são comuns e que a compreensão dos sintomas e do tratamento da diarréia deve ser prioritária na área de saúde. RAMOS et alii (1978) discorrem sobre a gravidade da diarréia em unidade de berçário que pode determinar surtos epidêmicos de proporçāo variável. Comentam, tambem, que é muito im- 
portante a profilaxia da diarréia do recém-nascido, citando uma série de medidas que devem ser adotadas pelo pessoal do berçário: isolamento, afastamento dos portadores, tratamento do doente e alimentação.

Constatou-se ainda que apenas 2 atendentes da amostra incluem-se na categoria "Muito Bom" em relação à questāo n' 20, "cuidado com o prematuro que está apresentando vômitos", $17(51,50 \%)$ classificaram-se na categorịa de conhecimentos "Bom", $10(30,30 \%)$ no conhecimento "Regular" e 12,12\% no conhecimento "Insuficiente".

Para CORRADINI et alii (1978) o vômito é uma das causas de desidratação do recém-nascido. Este, por sua vez, tem como causa, além de outras, a alimentação inaciequada como: volume excessivo, concentraçāo elevada, mamadas muito freqüentes, deglutição de ar, qualidade de alimento, etc.

Pode-se, portanto, avaliar a importância da assistência adequada de enfermagem, tanto na profilaxia como no tratamento do vômito.

Do total das atendentes da amostra, nenhuma classificou-se no conhecimento "Muito Bom", 48,49\% no conhecimento "Bom" e $51,51 \%$ no conhecimento "Regular" na sobre a limpeza e conservação da incubadora.

Considerando que a morbidade causada por infecção influi no aumento da mortalidade neonatal, os componentes da equipe de enfermagem devem empregar os princípios de antissepsia corretamente, para preveni-la. Segundo FREDDI \& BARBIERI (1979), quando existe boa assistência de enfermagem, a infecçāo ê reduzida ao mínimo. Entre as medidas especiais para prevenir infecção, incluem-se os cuidados com a incubadora que visam a sua limpeza e sua conservação. $\mathrm{Na}$ análise dos dados apresentados constata-se que $100 \%$ das atendentes da amostra não têm conhecimento correto sobre estes cuidados. Isto deve alertar as enfermeiras para a orientaçāo da atendente em serviço.

O conhecimento sobre "cuidado com o prematuro que está em fototerapia" (questão $n^{\circ}$ 24) é de importância para a enfermagem, pois este tratamento é comumente utilizado quando os níveis de bilimubina são altos. Sabe-se que a fototerapia apresenta outros efeitos além de reduzir os níveis séricos de bilimubina, como: vasodilatação periférica, aumento considerável da perda insensível de água, redução do tempo de trânsito intestinal e outros ZIEGEL \& CRANLEY (1980). Cuidados com a máscara utilizada para vendar os olhos do recém-nascido, prevenindo lesōes dos olhos e escoriações da cómea, observar a estimulação sensorial do recém-nascido durante a alimentação (retirando a venda dos olhos, pegando-o no colo, além de outros) é um cuidado importante de enfermagem, como também a manutenção do aparelho em condiçōes ótimas.

Entretanto 25 atendentes $(75,75 \%)$ se incluem no conhecimento "Bom", somente $8(24,25 \%)$ foram classificadas dentro do conhecimento "Muito Bom".

Verifica-se que $28(53,86 \%)$ atendentes da amostra estão classificadas no 
conhecimento "Bom" na pergunta sobre técnicas do banho na incubadora (questão no 14). Embora este conhecimento seja imprescindível na assistência de enfermagem, nota-se que os conhecimentos classificados como "Bom" e "Regular", compreendem $57,70 \%$ desta população. Dentro do conhecimento classificado como "Muito bom" estāo incluídas $22(42,30 \%)$ atendentes.

Outro fato interessante é que a maioria das atendentes, $24(72,72 \%)$, classificou-se no conhecimento "Muito bom" em relaçâo à vista da mãe ao prematuro no berçário, (questāo n-25). As $9(27,28 \%)$ atendentes restantes foram classificadas no critério de conhecimento "insuficiente", pois informaram que a visita da mãe seria prejudicial ao prematuro. Nesta questão foi considerada ápenas duas alternativas, conforme o critério estabelecido, "Muito bom" - visita é benéfica ao prematuro e "Insuficiente" - visita é prejudicial ao prematuro.

KLAUS \& KENNEL (1978) afirmam que o papel da mãe no serviço de neonatologia para o recém-nascido de baixo peso, tem sido muito importante ultimamente. Estes recém-nascidos dependem totalmente de sua mãe para satisfazer todas suas necessidades físicas e emocionais. $O$ carinho da mãe $e$ absolutamente indispensável para um ótimo crescimento e desenvolvimento do fillho prematuro.

FREDDI \& BARBIERI (1979) destacam a possibilidade da enfermeira em manter aberta as vias de comunicação entre ela e os pais do recém-nascido prematuro internado, sempre ajudando-os a vencer a crise familiar que se instalou. A assistência da mãe ao seu filho prematuro deve ser estimulada pela enfermeira, pois esta é benéfica para o bom relacionamento entre mãe, filho e família.

Segundo REYNOLDS (1973 a, b) a importância de dar aos pais a oportunidade de ver e tocar em seu filho, mesmo quando este está na incubadora, é maior do que o perigo de infecçāo. Quando os pais têm livre acesso à unidade, eles têm mais probabilidade de criar laços firmes com seus filhos dos quais estão afastados e muitas dificuldades que podem surgir quando o bebê for para casa serão evitadas.

A enfermeira nāo faz parte do quadro de pessoal do berçário de muitas maternidades, cujos administradores, observando o mínimo de requisitos para o credenciamento junto aos órgãos governamentais, contratam poucos desses profissionais de nível universitário, alocando-os prioritariamente em outras unidades, MONETTI \& CARVALHO (1976). Conseqüentemente, como já foi mencionado, as atendentes representam a maioria dentro da equipe de enfermagem que assiste ao recém-nascido prematuro.

Embora sem qualificaçāo profissional, SÃO PAULO. Leis, decretos, etc (1980), a atendente é o elemento da equipe de saúde mais freqüente nas maternidades brasileiras. Devido a isso, há necessidade de maior orientaçāo e de programa de treinamento de atendente, seguido de uma supervisāo em serviço contínua.

Em nosso estudo, 33 atendentes informaram que receberam orientaçāo de 
profissionais do serviço. Contudo, os dados analisados mostram que há necessidade de melhor preparo da atendente para executar as atribuiçöes relativas à assistência do recém-nascido prematuro, pois em 12 questões do formulário, a maioria classificou-se na categoria de conhecimento "Bom".

Das 33 atendentes da amostra, $31(93,90 \%)$ classificaram no conhecimento "Bom" em 8 a 14 questōes do formulário. Outro dado interessante é que 33 atendentes $(100,00 \%)$ responderam "correto", classificando-se na categoria de conhecimento "Muito bom" em 2 a 9 questões do formulário.

Contudo, apenas quatro atendentes responderam 14 questōes classificadas como "Bom" e nenhuma atendente da amostra emitiu além de 14 respostas nos diferentes critérios estabelecidos.

No índice zero de respostas, notamos que 21 atendentes năo tiveram respostas "totalmente errada" (Insuficiente).

Portanto, verificamos que as atendentes da amostra, de modo geral, tem conhecimento sobre "características físicas do prematuro e alguns cuidados de enfermagem aplicados ao mesmo estando ou nāo com complicaçōes". Notamos que o índice de respostas classificadas como "Muito bom" e "Bom" é bem maior em relaçăo ao índice de respostas classificadas como "Regular" e "Insuficiente".

Em estudo anterior realizado com as atendentes que trabalham no período diurno, MERIGHI (1984), obtivemos resultados que diferem deste. Na questāo relativa à "observção do prematuro nas primeiras $24 \mathrm{~h}$ de vida", 28,84\% das atendentes do período diumo classificaram-se na categoria "Muito bom", enquanto neste trabalho nenhuma atendente obteve esta classificação. $O$ mesmo se verifica com respeito às questōes sobre "características físicas do prematuro" onde nenhuma atendente classificou-se no conhecimento "Muito bom", enquanto que as atendentes que trabalhavam no periodo diumo, 17,30\% classificaram-se no conhecimento "Muito bom".

Comparando os resultados deste trabalho com o apresentado anteriormente, com respeito à "alimentação do prematuro com mamadeira" verificamos que $55,76 \%$ das atendentes do seu estudo afirmaram saber corretamente a técnica, o que nāo ocorreu neste trabalho, onde somente $24,25 \%$ responderam certo, classificando-se na categoria "Muito bom" nesta questāo. O mesmo podemos observar comparando os resultados sobre o conhecimento em relaçāo à alimentaçāo do prematuro com sonda naso-gástrica onde $48,07 \%$ das atendentes do período diurno incluem-se no conhecimento "Muito bom", enquanto que apenas 33,33\% das atendentes do noturno estão classificadas nesta categoria.

Outros dados relevantes em estudo comparativo destas duas pesquisas referem-se aos cuidados com o prematuro após a alimentação, técnica do banho do prematuro na incubadora, cuidados ao prematuro que está apresentando vômitos, limpeza e conservação da incubadora, cuidados ao prematuro que está recebendo 
oxigênio e controle da umidade da incubadora, onde a maioria das atendentes que trabalnam em berçário durante o dia demonstram ter conhecimento "Muito bom" em contraste com as que trabalham durante a noite cuja minoria obteve esta classitiçaçāo.

\section{CONCLUSÕES}

Le acordo com os objetivos propos os e dos dados obtidos foi possivel concluir que as atenden es de enfermagem tem conhecimento classificado segundo o critério estabelecido como "Bom" com relação às características físicas do prematuro e alguns cuidados de enfermagem dados ao mesmo, estando ou não com complicaçōes.

Isto, porém, não nos satisfaz, ou mesmo, nos preocupa porque a população de prematuros é considerada de alto risco. $\mathrm{O}$ atendimento a esses recém-nascidos deve ser prestado por enfermeira. Cabe-nos refletir sobre o fato de se delegar às atendentes atividades que nāo são de sua competência e para as quais nāo estão capacitadas.

Supomos que um estudo qualitativo da Assistència prestada por estas atendentes nos daria outros resultados.

MERIGHI, M.A.B. Knowledge of nursing aids on care given to premature newborns. Rev. Esc. Enf. USP, Sāo Paulo, 23(2):-_, Aug 1989.

The objective of this study as to verify the knowledge nursing aids, working night ir. premature nurserym on physical characteristics of premature newborns and on some prodedures done to them, eitheir experiencing complications or not. The population of this study was of 33 nursing aids of 12 hospitals of Grande São Paulo. The data were obtained, through internew using a structured form. Ecletic criteria was used to evaluate the knowledge of the nursing aids, and classified in the categories of "very good", "good", "regular", and "poor". Through the data obtained, we verified that the nursing aids have knowledge classified as "good" in relation to physicl characteristics of the premature newborn and also" to the nursing care givem to them, whem not experiencing complications.

UNITERMS - Nurses' aids. Infant, premature. Neonatal nursing.

\section{REFERÊNCIAS BIBLIOGRÁFICAS}

ACADEMIA AMERICANA DE PEDIATRIA. Normas y recomendaciones del recién nascido in hospitaic: a termino y prematuro Evanston, 1957. p. 7-133.

ARAUJO, 3. Patologia do umbigo. In: AlCANTARA, P. \& MARCONDES, E. Pediatria básica 6. ed. Säo Paulo, Servier, 1978. p. 585.

BETHEA, D. C. Peso bajo al nacer y prematuros. In: —__ Enfermeira maternoinfantil 2. ed. México, Interamericana, 1977 . cap. 20 , p. 223-9.

CENTRO DE ESTUDOS PERINATAIS DE SÃO PAULO. Normas de assistência hospitalar aos recém-nascidos Säo Paulo, Nestlé, 1972. 
CORRADINI, H. B. et alii. Recerm-nascido de baixo peso ao nascimento. In: ALCANTARA, P. \& MARCONDES, E. Pediatria básica. 6. ed. Săo Paulo, Sarvier, 1978. v. 1, p. 461-71.

CROSSE, M. The premature baby. 4. ed. London, Churchill, 1957. p. 125-46.

FREDDI, W. E. da S. \& BARBIERI, D. L. Responsabilidade da enfermeira na assisténcia ao recém-nascido de alto risco. Rev. Esc. Ent. USP, Såo Paulo, 13(1): 69-88, abr. 1979.

KLAUS, H. M. \& FANAROFF, A. Alto risco em neonatologia. 2.ed. Rio de Janeiro, Interamericana, 1982 . cap. 7, p. 141-66.

\& KENNEL, J. H. La relacion madre hijo: impacto de la separacion o perdida prematura in el desarrolho de la familia. Buenos Aires, Panamericana, 1978. capl, p.15-7.

LANCASTER, J. \& ROBERTS, F. B. Impact os intensive care on the maternal-infant relationship. In: KORONES, S. A. High-risk newborn infants. 2. ed. Saint Louis, Mosby, 1972. cap. 12, p. 217-22.

LLORENS, J. et alii. El prematuro y su cudado. In:_—_ Pediatria para enfermeras. Barcelona, Jims, 1972. cap. 15, p. 223-38.

MAURO, M. Y. C. et alii. Fadiga e aspectos ergonómicos no trabalho de enfermagem Rev. Bras. Enf. Brasflia, 29(4):7-18, out./dez. 1976.

MERIGHI, M. A. B. Conhecimento da atendente de enfermagem que trabalha em berçário de prematuro, sobre determinados cuidados de enfermagem dados a estes recém-nascidos. Såo Paulo, 1984. 87 P.. (Dissertaçăo de Mestrado - Escola de Enfermagem da USP).

MILLER, B. F. \& BURT, J. J. Salud individual y coletiva: el hombre y la sociedade actual. México, Interamericana. 1973. p. 291-94.

MONETTI, V. \& CARVALHO, P. R. Mortalidade materna e na infáncia no Estado de Săo Paulo: aspectos demográficos, sócio-culturais e médico-sanitários. Såo Paulo, Instituto de Saúde, 1976. p. 45-50.

MORLEY, D. Pediatria no mundo em desenvolvimento: Prioridades. Sāo Paulo, Paulinas, 1980. p. 144.

MOURA, L. R., LULATO, L. H.; PARD, M. G. Assistencia de enfermagem no plantăo noturno. Rev. Bras. Enf. Brasflia, 33(2): 253-54, abr Jjun. 1980.

ORLANDI, O. V. O prematuro. Rio de Janeiro, Capit6lio, 1954. p. 13-114.

RAMOS, S. L. et alii. Infecçōes neonatais. In: ALCANTARA, F. \& MARCONDES, E. Pediatria básica. 6. ed. Sáo Paulo, Sarvier, 1978. p. 548-52.

REYNOLDS, E. O. R. Neonatal intensive care. Nurs. Times, London, 69(37):1178-81, Sept. 1973 (a).

REYNOLDS, E. O. R. Neonatal intensive care. Nurs. Times, London, 69(38):1220-1, Sept. 1973 (b).

ROSSIER, A. Fisiopatologia de la prematuridade. In: — El preamturo. Buenos Aires, Panamericana, 1974. cap.3,p.27-54(a).

ROSSIER, A. Fisiopatologia de la prematuridade. In: - El preamturo. Buenos Aires, Panamericana, 1974. cap.16,p.156-5(b).

SĀo PAULO. Leis, decretos, etc. Projeto de Lei no 5.487 de 1980 . Dispóe sobre a prestaçăo da assisténcia de enfermagem nas instituiçōes de saúde públicas e privadas e de outras providências. $9 \mathrm{p}$.

SCHAFFER, A. J. \& AVERY, M. E. Outras infecçסes bacterianas especificas. In:_— Doenças do recém-nascido. Rio de Janeiro, Interamericana, 1979. cap. 86, p. 697.

TURNER, C. E. Higiene del individuo y de la comunidade. 2.ed. Mexico, Centro Regional de Ayuda Técnica. 1964. p. 46-52.

VERONESI, R. et alii. Tétano. In: AlCANTARA, P.\& MARCONDES, E. Pediatria básica. 6. ed. Săo Paulo, Sarvier, 1978, p. 1036.

ZIEGEL, E. \& CRANLEY, M. Reckm-nascido de alto risco. In: Enfermagem obstetrica. 7. ed. Rio de Janeiro, Interamericana, 1980 . cap. 25, p. 559-96. 
1. Idade (em anos)

2. Ate que ano a Sra. frequentou a escola?

3. Tempo de trabalho em berçário de recém-nascido prematuro

4. Profissional responsável pela orientaçăo em serviço: enfermeira ( ) pediatra ( ) neonatologista ( )

\section{B - DADOS SOBRE O CONHECIMENTO DAS ATENDENTES SOBRE PREMATURO E CUIDADOS DE ENFERMAGEM AO MESMO.}

5 - O que a Sra. sabe quanto ds características fisicas do prematuro?

Caracteres ffsicos do prematuro:

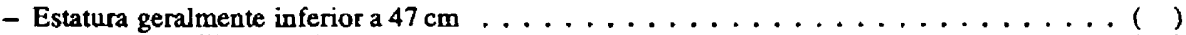

- Perímetro cefálico inferior a $3 \mathrm{~cm} \ldots \ldots \ldots \ldots \ldots \ldots \ldots$. . . . . . . .

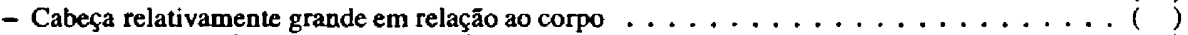

- Fontanela bregmática ampla e lambdóide aberta . . . . . . . . . . . . . ( )

- Ossos da abóbada craniana separados . . . . . . . . . . . . . . . . . ( )

- Pavilhóes auriculares moles, pequenos e afastados da cabeça . . . . . . . . . . ( )

- Pescoço mais curto do que o de um recém-nascido a termo . . . . . . . . . . . . . . ( )

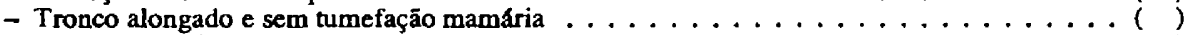

- Perfmetro torácico maior que o cefálico ..................... ( )

- Queda do coto umbilical mais tardia do que de um reckm-nascido a termo . . . . . . . . ( )

- Pernas curtas e delgadas . . . . . . . . . . . . . . . . . . . ( )

- Clitoris de tamanho exagerado, simulando, muitas vezes, um pénis . . . . . . . . . ( )

- Ausencia freqüente de testículo na bolsa excrotal . . . . . . . . . . . . . . ()

- Pele enrugada, recoberta por lanugem; avermelhada nos primeiros dias, freqüentemente ictérica a seguir. Através da pele pode-se perceber vasos sangülneos . . . . . . . . . ( )

- Tecido celular subcutaneo escasso . . . . . . . . . . . . . . . . . . ()

- Unhas reduzidas, nem sempre alcançam as extremidades dos dedos . . . . . . . . . . ()

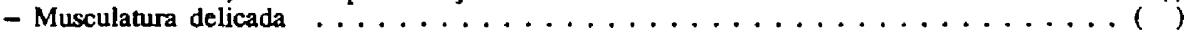

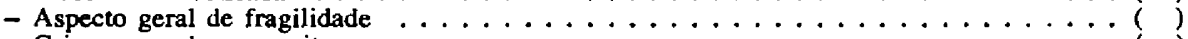

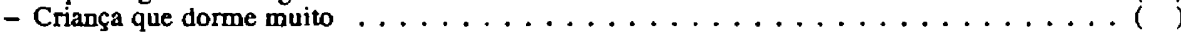

6 - Qual a observaçăo que a Sra, acha que deve ser feita nas primeiras 24 h de vida?

Observação do prematuro nas primeiras $24 \mathrm{~b}$ de vida.

- Observaçăo ccınstante quanto a presença constante de cianose, palidez e icterf́cia . . . . . . ( )

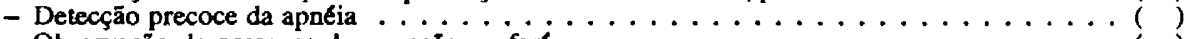

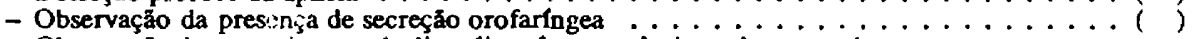

- Observação do aparecimento de dispnéia, náuseas, vómitos e hemorragias

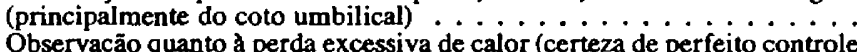

- Observação quanto à per

- Observaçáo da primeira eliminaçăo de mecônio e de urina .............

7 - Para a Sra. como deve ser feita a hidratação do prematuro?

Hidrataçăo do prematuro:

- Iniciar por via oral, assim que as condiçőes do prematuro o permitarn, quatro a seis

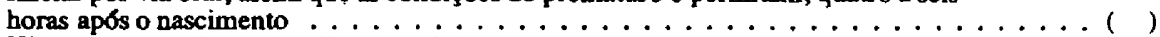

- Hidratar com solução de glicose a $10 \%$ ou a $20 \%, 2$ a 3 ml . . . . . . . . . . . ()

- Hidratar de duas em duas horas (nos intervalos das mamadas) $\ldots \ldots \ldots \ldots \ldots \ldots$. 
8 - Para a Sra. quais os cuidados que se deve ter ao alimentar o prematuro com mamadeira.

- Alimentaçăo do recém-nascido prematuro com mamadeira.

- Bico macio, com oriffcio nảo muito pequeno (para verificar se o tamanho do oriffcio está adequado, inverte-se a mamadeira, o leite deverá gotejar por este oriffcio) . . . . . . ( )

- Elevar a cabeceira da incubadora ou do berço ..................... ( )

- Dar a mamadeira, verificando sempre se nao há ar entre o bico e o gargalo da mamadeira ... ()

9 - Para a Sra. de que maneira deve ser ministrada a alimentaçāo do prematuro por sonda naso-gástrica?

Alimentaçăo do prematuro por sonda naso-gástrica.

- Verificar sempre antes de introduzir o alimento, se a extremidade da sonda está no estômago, fazendo aspiraçắo do conteúdo gástrico com a seringa . . . . . . . . ( )

- Introduzir o alimento na sonda pela extremidade livre desta, por intermédio de uma seringa, deixando-o escoar livremente, com a pressåo do embolo ........... ( )

- Terminada a alimentaçăo proceder a limpeza da sonda, injetando nesta $2 \mathrm{ml}$ de soro glicosado a $5 \%$ (ou de água fervida) e fechar a extremidade livre com um conector . . . . . . . . . ( )

10 - A Sra. poderia nos dizer como deve ser passada a sonda naso-gástrica?

T\&cnica de gavage.

Material:

- mamadeira graduada contendo leite em quantidade prescrita $\ldots \ldots \ldots \ldots \ldots \ldots \ldots$ )

- seringa de $20 \mathrm{ml} \ldots \ldots \ldots \ldots \ldots \ldots \ldots$ )

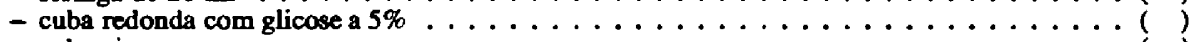

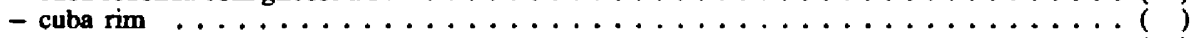

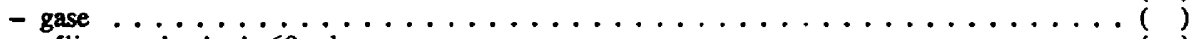

- cálice graduado de $60 \mathrm{ml} \ldots \ldots \ldots \ldots \ldots \ldots \ldots \ldots \ldots \ldots$ )

\section{Metodo:}

- verificar se a quantidade, a dosagem e o nome do leite a ser dado conferem com a prescriç̆o medica ................... ( )

- colocar o material sobre a mesa. Pegar a sonda com gase estéril e medir a distancia da raiz do nariz ate o apendice xifóide, marcando-a com fita adesiva ........... ( )

- pegar a sonda, envolvida com gase estéril e iniciar a sua introduçăo, lentamente, pela narina, até a marca feita na mesma, observando a reacăo do reckm-nascido . . . . . . . ( )

- caso a criança apresente tosse, dispnéia ou cianose, apertar a sonda e retirá-la; reiniciar

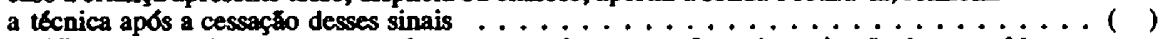

- verificar se a sonda se encontra realmente no estómago, ou fazendo aspiraçăo do conteúdo gástrico com a seringa ou colocando a extremidade da sonda na cuba redonda de água, para observar se há presença de ar pela formaçăo de bolhas $\ldots \ldots \ldots \ldots \ldots \ldots \ldots$ )

- trocar a sonda naso-gástrica cada quatro dias, com o cuidado de usar a outra narina para

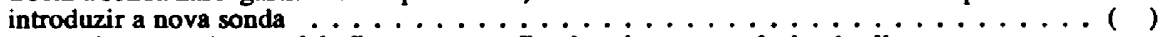

- para retirar a sonda aperta-la firmemente, a fim de evitar que gotóculas de alimento ou

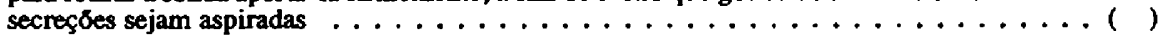

11 - Qual o cuidado que a Sra. acha que deve ser dado ao prematuro apos a alimentaçåo?

\section{Cuidado do prematuro aposs a alimentaçăo:}

- Inspecionar o interior da boca verificando se todo o alimento já foi deglutido, para evitar que a alimentaçăo retida na boca seja aspirada ....................

- Facilitar a eructaç̧o do prematuro (colocar a măo esquerda espalmada sob as costas do RN, conservando o polegar na parte posterior do tórax e os outros dedos na axila mantendo a măo esquerda nesta posiçato ate o prematuro eructar ......................

- Retirar da pele as gotas de alimento que por acaso tenham cafdo evitando-se assim, irritaçắo da mesma

- Deitar o prematuro em decúbito lateral, para evitar que o alimento regurgitado ou vomitado

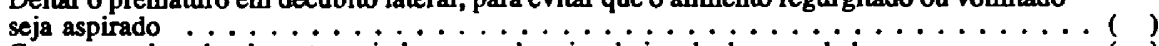

- Conservar elevada, durante meia hora, a cabeceira da incubadora ou do berço . . . . . . . ( ) 
12 - Por favor, descreva a tónica do banho do prematuro na incubadora:

TEcnica do banho na incubadora.

Material:

- bolas de algod\$o, compressas estereis, agua fervida morna, cuba rim . . . . . . . . . ( )

Metodo:

- iniciar pela limpeza dos olhos, paseando levemente, sobre a palpebra de cada olho, com movimento da parte interna para a externa, uma bola de algodßo, estfril embebida em água,

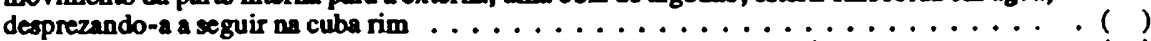

- limpar as narinas com fusos de algodso umedocidos, um para cada narina . . . . . . . . ( )

- limpar as dobras do pavilhso auricular com fusos de algod\$o, um para cada orelha . . . . . . ( )

- limpar a face com bolas de al godso, embebidas em água: enxugar com compressas . . . . . ( )

- levantar a cabega e 06 ombros do reckm-nascido, como descrito na tecnica da al imentaça

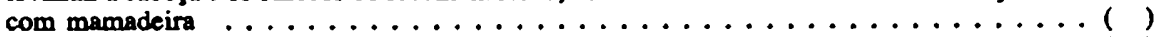

- lavar a boca com bolas de algodso embebidas em agua morna; enxugar . . . . . . . . . ( )

- limpar as dobras do pescoço, axilas, braços com bolas de algodaso embebidas em água e enxugar com compressas . . . . . . . . . . . . . . . . . . . . . ( )

- limpar a regiano inguinal, dobras das pernas, pts e entre os artelhos, seguindo a mesma

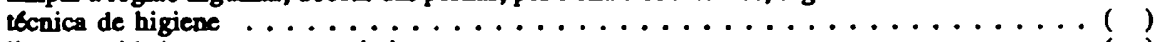

- limpar cuidadosamente os genitais ....................... ( )

- a) sexo feminino - limpar os grandes lábios com algodøo embebido em água, sempre de cima

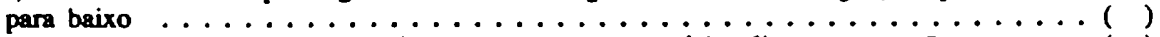
b) sexo masculino - fazer com cuidado a retraçăo do prepucio e limpar a secreçăo . . . . . . ( )

- fazer o curativo umbilical . . . . . . . . . . . . . . . . . . . . ( )

- anotar as eliminaçסes e as alteraçoes observadas na pele (cor, pustulas, irritaçóes, etc.) na postura e no coto umbilical, sangramento, secregoes, granulomas, etc. . . . . . . . . . . . )

13 - Para a Sra. quais slo os cuidados que devemos ter com a pele do prematuro para evitar infecçסes?

Cuidado da pele do prematuro para evitar infecgsto:

- a pele deve ser limpa, diária e cuidadocamente, com algadåo embebido em água, evitando traumatizs-la, pois \& muito fina e delicada ............... ( )

- observar se nio ho irritaçlo, ferimentos ou pustulas . . . . . . . . . . . . . ( )

- apbs as miçóes e evacuaçós limpar os orghtos genitais . . . . . . . . . . . . . . . )

14 - A Sra. poderia enumerar os cuidados com o coto umbilical?

Cuidado do coto umbilical:

- Limpar as pregas da base com cotonete umedecido com água oxigenada, secá-lo com gase ............................ ()

- tocar o coto umbilical com mertiolate ....................... ()

- anotar o que foi realizado e 0 aspecto do coto: sangramento, socreç̆o, cor, tumefaçăo ..... ( )

- manter o coto umbilical limpo e seco ......................... ()

15 - A Sra. poderia descrever os cuidados com o prematuro com moniliase?

Cuidado com o premturo com moniliase:

- lavar bem as mslos com agua e antisséptico antes de cuidar do prematuro . . . . . . . . . ( )

- fazer a limpeza da boca do prematuro com água bicarbonatada, usando uma espátula com a extremidade envolvida em gase, ou com cotonetes; pasas-la por toda a cavidade bucal ( )

- lavar muito bem com água e sabso, e esterilizar todo o material usado com o prematuro ... ( ) 
16 - A Sra. poderia descrever os cuidados prestados ao prematuro que está com problemas respiratórios?

Cuidados do prematuro com problemas respiratórios:

- elevar a cabeceira do leito. Aspirar, sempre que nocessário a secreçăo nasofaríngea . . . . . ( )

- suspender a alimentaçăo assim que o prematuro demonstrar dificuldade respiratória . . . . . ( )

- vigiar constantemente a respiraçăo do reckm-nascido, para detectar a presença de apntia ... ( )

- vigiar a oxigenaçăo, o controle da umidade e o aquecimento da isolete . . . . . . . . ( )

17 - Para a Sra. quais os cuidados a serem dados com o prematuro que está apresentando diarréia?

Cuidados do prematuro com diarreia:

- no caso do prematuro evacuar mais de 6 vezes por dia ou de apresentar fezes líquidas ou esverdeadas:

- avisar o medico imediatamente ....................... ( )

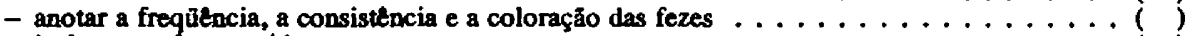

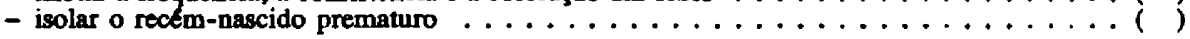

18 - Como a Sra. cuida de um prematuro que está apresentando vômitos?

Cuidados do prematuro com vớmito:

- observar e anotar se o vómito $\epsilon$ em jato ou năo, se ocorre após a alimentaçăo e

sua freqütncia e quantidade $\ldots \ldots \ldots \ldots \ldots \ldots \ldots \ldots \ldots \ldots \ldots \ldots \ldots \ldots \ldots \ldots \ldots$ )

- colocar o bebe em decábito lateral e aspirar sempre que for necessário . . . . . . . . ( )

- suspender a alimentaç̆ơ se houver náuseas ou vômitos

19 - Como a Sra. acha que deve ser feita a limpeza e conservaçăo da incubadora?

Limpeza e conservação da incubadora:

- lavar diariamente a parte interna e externa da incubadora com pano, água e sabăo

(ou soluçăo antisséptica) e enxugar com um pano seco $\ldots \ldots \ldots \ldots \ldots \ldots \ldots$ )

- fazer a limpeza terminal da incubadora após a retirada da criança

(desmontando-a toda, lavando-a com agua e sabăo ou soluçăo antisséptica ......... ( )

- deixar arejar a incubadora durante 6 horas, antes de prepara-la para nova admissáo. Se possfvel trocar a criança de incubadora cada quinze dias, para a limpeza terminal . . . . . . ( )

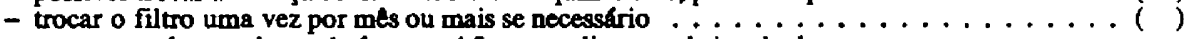

- nunca usar éter em lugar de água e sabăo para a limpeza da incubadora ou para

qualquer cuidado administrado à criança na incubadora, pois o eter combinado com o

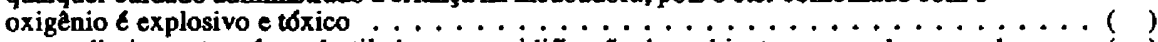

- trocar diariamente a água destilada para umidificaçäo do ambiente no caso de ser usado ... ()

20 - Quais săo os cuidados prestados ao prematuro que está recebendo oxigénio?

Cuidados com o prematuro que está recebendo oxigenio:

- seguir rigorosamente a prescriçâo médica e o número de litros por minuto a ser administrado ( )

- verificar o funcionamento do conjunto: manometro, umidificador, intermediário de borracha e funil . . . . . . . . . . . . . . . . . .

- fixar o intermediário de borracha no lençol que cobre o coxim com fita adesiva e

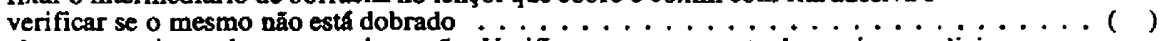

- observar a criança durante a oxigenaçăo. Verificar o ressecamento das narinas e adicionar água destilada no umidificador até o limite permitido

21 - Como a Sra. controla a umidade da incubadora?

Controle da umidade da incubadora:

- controlar a umidade de acordo com a prescriçăo médica $\ldots \ldots \ldots \ldots \ldots \ldots \ldots$. . . )

- trocar a água destilada diariamente de acordo com o horário estabelecido . . . . . . . . ( ) 
22 - Quais sáo os cuidados com o prematuro que estâ em fototerapia?

Cuidado do prematuro em fototerapia.

- antes do infcio do tratamento, proteger os olhos do recém-nascido, cuidadosamente, com gase e pano escuro . . . . . . . . . . . . . . . . . . ( )

- conservar o prematuro completamente despido, para que a incidencia da luz seja uniforme, em toda a superficie cutânea; mudar o recem-nascido de posiçăo pelo menos de duas em duas horas, alternando decúbito dorsal e ventral $\ldots \ldots \ldots \ldots \ldots \ldots \ldots \ldots$. . . . . . .

- observar o estado de hidrataçato do rectm-nascido observando as fezes e hidratá-lo a intervalos de 1 hora e 30 minutos

- controlar a temperatura do prematuro cada 4 horas

Cuidado com o aparelho:

a) - antes de ligá-lo verificar cuidadosamente a parte elétrica: fio conector, tomada, fio terra e amperagem $\ldots \ldots \ldots \ldots \ldots \ldots \ldots$ )

b) - manter a temperatura do berço em torno de $300 \mathrm{C} \ldots \ldots \ldots \ldots \ldots \ldots$ ()

c) - manter as lampadas numa distancia de 40 a $50 \mathrm{~cm}$ da superficie que será irradiada ... ()

d) - anotar o tempo de uso da limpada e substituf-la apos 200 horas de uso .......... ( )

23 - A Sra. acha que a visita diária da măe ao prematuro internado seria:

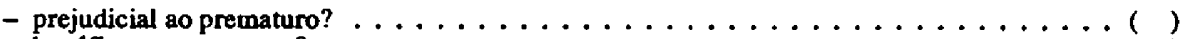

- benefica ao prematuro?

Visita da măe ao seu filho prematuro.

Sempre que possivel fazer os pais compartilharem da assistencia à criança, pois a interaçăo măte $e$ filho é benefica para ambas as partes; comunicar a măe o progresso do prematuro pelo menos uma vez ao dia ou mais freqüentemente.

Recebido para publicaçło em 30/06/88. 